\title{
Anna Łyczkowska-Hanćkowiak
}

Wyższa Szkoła Bankowa w Poznaniu

e-mail: anna.lyczkowska-hanckowiak@wsb.poznan.pl

\section{SKIEROWANA BEHAWIORALNA WARTOŚĆ BIEŻĄCA - ZREWIDOWANE PODEJŚCIE ORIENTED BEHAVIOURAL PRESENT VALUE - REVISED APPROACH}

DOI: $10.15611 / \mathrm{pn} .2018 .533 .15$

JEL Classification: C44, C02, G10

Streszczenie: Behawioralna wartość bieżąca (BPV) jest rodzajem wartości bieżącej, która zależy od czynników behawioralnych. Punktem wyjścia do rozważań jest BPV zdefiniowana jako liczba rozmyta typu L-R. W artykule BPV została opisana za pomocą zrewidowanej definicji skierowanej liczby rozmytej. Informacje opisane przez BPV uzupełniono o subiektywną prognozę kierunku trendu ceny rynkowej. Prognoza została wprowadzona w modelu BPV jako orientacja liczby rozmytej. Domniemanie wzrostu ceny rynkowej zaznaczono za pomocą dodatniej orientacji liczby rozmytej. Domniemanie spadku ceny rynkowej zaznaczono za pomocą ujemnej orientacji liczby rozmytej. Na koniec pokazano, że przy założeniu, że wartość przyszła jest zmienną losową o rozkładzie normalnym, oczekiwany czynnik dyskontujący może zostać przedstawiony jako skierowana liczba rozmyta. Orientacja oczekiwanego czynnika dyskontującego jest zgodna z orientacją BPV, która go definiuje.

Słowa kluczowe: behawioralna wartość bieżąca, skierowana liczba rozmyta, czynnik dyskontujący.

Summary: Behavioural present value (BPV) is such a kind of present value which is depended of behavioural factors. The starting point for our discussion is BPV defined as a L-R fuzzy number. In this work BPV was described using the revised definition of ordered fuzzy number. The information described by BPV were supplemented with a subjective forecast of the orientation of the market price trend. This forecast is implemented in the model BPV as an orientation of the positive fuzzy number. The presumption of market price increase is described by the positive orientation of fuzzy number. The presumption of market price decrease is described by the negative orientation of fuzzy number. At the end it is shown that, with the assumption that future value is a random variable under Gaussian distribution of probability, the expected discount factor is determined as ordered fuzzy number. The orientation of expected discount factor is consistent with the orientation of the BPV defining it.

Keywords: behavioural present value, ordered fuzzy number, discount factor. 


\section{Wstęp}

Przez wartość bieżącą (PV) rozumiemy wartość teraźniejszego ekwiwalentu płatności dostępnej w ustalonym momencie czasu [Piasecki 2011]. Wartość bieżąca PV przyszłych przepływów finansowych może być nieprecyzyjna. $\mathrm{Z}$ tego powodu PV została opisana przy użyciu liczb rozmytych.

W pracach [Piasecki 2011] oraz [Piasecki, Siwek 2015] behawioralna wartość bieżąca (BPV) została zdefiniowana jako przybliżenie aktualnej ceny rynkowej, która jest nieprecyzyjnie oszacowana pod wpływem czynników behawioralnych. W [Łyczkowska-Hanćkowiak 2017a; Łyczkowska-Hanćkowiak 2017b] informacja opisana przez BPV została uzupełniona o subiektywną prognozę trendu ceny rynkowej. Prognoza ta została wprowadzona w modelu BPV jako orientacja liczby rozmytej. W ten sposób BPV zastąpiono przez zorientowaną BPV zdefiniowaną za pomocą skierowanej liczby rozmytej [Kosiński i in. 2003]. W tym artykule behawioralną wartość bieżącą opisano za pomocą zrewidowanej definicji zorientowanej liczby rozmytej podanej w [Piasecki 2018]. Dodatnia orientacja liczby skierowanej opisuje subiektywną prognozę wzrostu ceny rynkowej. Ujemna orientacja liczby skierowanej opisuje subiektywną prognozę spadku ceny rynkowej. W pracy [Piasecki, Siwek 2018] pokazano, że w analizie portfelowej bardzo dobrym narzędziem służącym do wyceny rozważanych papierów wartościowych jest oczekiwany czynnik dyskontujący.

\section{Elementy teorii skierowanych liczb rozmytych}

Liczba nieprecyzyjna jest to liczba osiągająca każdą z rozpatrywanych wartości W różnym stopniu. Powszechnie akceptowalnym modelem liczby nieprecyzyjnej jest liczba rozmyta, zdefiniowana jako podzbiór rozmyty na prostej rzeczywistej $\mathbb{R}$. Najbardziej ogólną definicję liczby rozmytej podali Dubois i Prade [Dubois, Prade 1978]. W pracy [Dubois, Prade 1980] został wyróżniony szczególny rodzaj reprezentacji liczby rozmytej zdefiniowany w następujący sposób. Dla dowolnego niemalejącego ciągu $\{a, b, c, d\} \subset \mathbb{R}$ lewa funkcja odniesienia $L_{s}:[a, b] \rightarrow[0,1]$ oraz prawa funkcja odniesienia $R_{s}:[c, d] \rightarrow[0,1]$ są półciągłymi z góry, monotonicznymi funkcjami spełniającymi warunek

$$
L_{S}(b)=R_{S}(c)=1 \text {. }
$$

Wtedy funkcja przynależności $\mu_{S}\left(\cdot \mid a, b, c, d, L_{S}, R_{S}\right) \in[0,1]^{\mathbb{R}}$ liczby rozmytej $\mathcal{S}\left(a, b, c, d, L_{S}, R_{S}\right)$ jest zdefiniowana za pomocą tożsamości

$$
\mu_{S}(x \mid a, b, c, d)=\left\{\begin{array}{cc}
0, & x \notin[a, d]=[d, a], \\
L_{S}(x), & x \in[a, b]=[b, a], \\
1, & x \in[b, c]=[c, b], \\
R_{S}(x), & x \in[c, d]=[d, c] .
\end{array}\right.
$$

1 Zauważmy, że wzór ten opisuje dodatkowo rozszerzoną notację przedziałową stosowaną w tym artykule. 
Tak zdefiniowaną liczbę rozmytą nazywamy liczbą rozmytą typu LR.

Pomysł skierowanych liczb rozmytych został intuicyjnie wprowadzony przez Kosińskiego i współautorów [Kosiński i in. 2002; 2003; Kosiński 2006] jako rozszerzenie pomysłu liczby rozmytej. Istotną wadą teorii Kosińskiego jest istnienie skierowanych liczb rozmytych, które nie są liczbami rozmytymi. Niemniej intuicyjne podejście Kosińskiego do pojęcia skierowanej liczby rozmytej jest bardzo użyteczne. $Z$ tego powodu teoria Kosińskiego została poprawiona w pracy [Piasecki 2018]. Użyteczność skierowanych liczb rozmytych wynika z faktu, że skierowana liczba rozmyta jest liczbą rozmytą uzupełnioną orientacją, rozumianą jako porządek na prostej rzeczywistej $\mathbb{R}$. Wspomniana orientacja może być dodatnia lub ujemna. Ujemna orientacja oznacza liniowy porządek na $\mathbb{R}$ od liczb większych do mniejszych. Ujemnie zorientowana liczba jest interpretowana jako liczba, która może zmaleć. Dodatnia orientacja oznacza liniowy porządek na $\mathbb{R}$ od liczb mniejszych do większych. Dodatnia orientacja jest interpretowana jako liczba, która może wzrosnąć. Orientację od $a \in \mathbb{R}$ do $b \in \mathbb{R}$ będziemy oznaczać symbolem $\llbracket a \nrightarrow b \rrbracket$.

Dla dowolnego monotonicznego ciagu $\{a, b, c, d\} \subset \mathbb{R}$ funkcja początkowa $L_{S}:[a, b] \rightarrow[0,1]$ oraz funkcja końcowa $R_{S}:[c, d] \rightarrow[0,1]$ są ciągłymi funkcjami monotonicznymi spełniającymi warunek $L_{S}(b)=R_{S}(c)=1$. Tożsamość (1) definiuje funkcję przynależności $\mu_{\overleftrightarrow{S}}\left(\cdot \mid a, b, c, d, L_{S}, R_{S}\right) \in[0,1]^{\mathbb{R}}$ skierowanej liczby rozmytej $\overleftrightarrow{S}\left(a, b, c, d, L_{S}, R_{S}\right)$. Przestrzeń wszystkich skierowanych liczb rozmytych oznaczamy symbolem $\mathbb{K}$.

Spełnienie warunku $a<d$ określa dodatnią orientację $\llbracket a \nrightarrow d \rrbracket$ skierowanej liczby rozmytej $\overleftrightarrow{S}\left(a, b, c, d, L_{S}, R_{S}\right)$. W takim przypadku funkcja początkowa $L_{S}$ jest niemalejąca, natomiast funkcja końcowa $R_{S}$ jest nierosnąca. Każda dodatnio zorientowana liczba rozmyta jest interpretowana jako liczba nieprecyzyjna, która może wzrosnąć.

Spełnienie warunku $a>d$ określa ujemną orientację $\llbracket a \rightarrow d \rrbracket$ skierowanej liczby rozmytej $\overleftrightarrow{S}\left(a, b, c, d, L_{S}, R_{S}\right)$. W takim przypadku funkcja początkowa $R_{S}$ jest niemalejąca, natomiast funkcja końcowa $L_{S}$ jest nierosnąca. Każda ujemnie zorientowana liczba rozmyta jest interpretowana jako liczba nieprecyzyjna, która może zmaleć.

W przypadku, gdy $a=d$, skierowana liczba rozmyta $\overleftrightarrow{S}(a, a, a, a)$ opisuje liczbę rzeczywistą $a \in \mathbb{R}$, która nie jest zorientowana.

\section{Zorientowana wartość bieżąca}

Wartość bieżąca (PV) jest zdefiniowana jako teraźniejszy ekwiwalent płatności dostępnej w ustalonym momencie czasu teraz lub w przyszłości. Powszechnie akceptowany jest pogląd, że wartość bieżąca PV przyszłych przepływów finansowych może być wartością przybliżoną. Naturalną konsekwencją takiego podejścia 
jest ocena PV za pomocą liczb rozmytych. Szczegółowy opis ewolucji tego modelu można znaleźć w pracy [Piasecki 2014]. Między innymi nieprecyzyjna PV może być oceniona za pomocą skierowanej liczby rozmytej [Łyczkowska-Hanćkowiak, Piasecki 2018a]. Następnie PV może być scharakteryzowana za pomocą monotonicznego ciągu $\left\{V_{s}, V_{f}, \breve{C}, V_{l}, V_{e}\right\}$, gdzie:

- $\check{C}$ jest ceną rynkową,

- $\left[V_{s}, V_{e}\right] \subset \mathbb{R}^{+}$jest przedziałem wszystkich możliwych wartości bieżących PV,

- $\left[V_{f}, V_{l}\right] \subset\left[V_{s}, V_{e}\right]$ jest przedziałem wszystkich wartości, które nie różnią się zauważalnie od ceny rynkowej $\check{C}$.

Zorientowana wartość bieżąca PV (OPV) jest oszacowana za pomocą skierowanej liczby rozmytej

$$
\overleftrightarrow{P V}=\overleftrightarrow{S}\left(V_{s}, V_{f}, V_{l}, V_{e}, L_{P V}, R_{P V}\right),
$$

gdzie $L_{P V}:\left[V_{s} ; V_{f}\right] \rightarrow[0 ; 1]$ jest lewą funkcją odniesienia, a $R_{P V}:\left[V_{l} ; V_{e}\right] \rightarrow[0 ; 1]$ jest prawą funkcją odniesienia. Jeżeli przewidujemy wzrost ceny rynkowej, to zorientowana wartość bieżąca OPV jest opisana za pomocą dodatnio zorientowanej liczby rozmytej. Jeżeli przewidujemy spadek ceny rynkowej, to zorientowana wartość bieżąca OPV jest opisana za pomocą ujemnie zorientowanej liczby rozmytej.

\section{Zorientowana rozmyta behawioralna wartość bieżąca}

Rozpatrzmy dowolny instrument finansowy, który jest przedmiotem obrotu na silnie efektywnym rynku finansowym. Cena rynkowa tego instrumentu może zmieniać się $\mathrm{w}$ czasie. $\mathrm{Z}$ tego powodu możemy mówić o trendzie ceny rynkowej. Równowaga finansowa jest stanem na rynku finansowym, w którym trend ceny rynkowej jest stały. Wartość ceny rynkowej $\check{C}$ jest równa cenie równowagi $C_{0}$ wyznaczonej za pomocą analizy technicznej lub fundamentalnej. W pracy [Piasecki 2011] została zdefiniowana wartość bieżąca PV jako funkcja użyteczności przepływu finansowego. Ta wartość bieżąca PV zależy od różnych subiektywnych oraz obiektywnych czynników. Z tego powodu odchylenie wartości bieżącej PV od ceny rynkowej jest nieprecyzyjne. Behawioralna wartość bieżąca (BPV) zależy od wybranych czynników subiektywnych. W pracach [Piasecki 2011; Piasecki, Siwek 2015] behawioralna wartość bieżąca BPV została określona jako liczba rozmyta typu LR zdefiniowana przez następującą funkcję przynależności $\mu_{B P V}$ :

- dla $\Delta C>0$

$$
\mu_{B P V}(x \mid \Delta C>0)=\left\{\begin{array}{cc}
\frac{\left(x-V_{\min }\right)(1+\delta C)}{\check{C}-V_{\text {min }}+\left(x-V_{\min }\right) \delta C} & \text { dla } x \in\left[V_{\text {min }} ; \check{C}\right] \neq\{\check{C}\}, \\
\frac{V_{\max }-x}{V_{\max }-\check{C}+\left(V_{\max }-x\right) \delta C} & \text { dla } \left.x \in] \check{C} ; V_{\text {max }}\right], \\
0 & \text { dla } x \notin\left[V_{\text {min }} ; V_{\text {max }}\right],
\end{array}\right.
$$


- dla $\Delta C \leq 0$

$$
\mu_{B P V}(x \mid \Delta C \leq 0)=\left\{\begin{array}{cl}
\frac{x-V_{\min }}{\check{C}-V_{\text {min }}+\left(x-V_{\min }\right) \delta C} & \text { dla } x \in\left[V_{\text {min }} ; \check{C}[,\right. \\
\frac{\left(V_{\max }-x\right)(1+\delta C)}{V_{\max }-\check{C}+\left(V_{\max }-x\right) \delta C} & \text { dla } x \in\left[\check{C} ; V_{\text {max }}\right] \neq\{\check{C}\}, \\
0 & \text { dla } x \notin\left[V_{\text {min }} ; V_{\text {max }}\right],
\end{array}\right.
$$

gdzie

- $V_{\min }$ jest maksymalnym dolnym oszacowaniem wartości bieżącej PV,

- $V_{\text {max }}$ jest minimalnym górnym oszacowaniem wartości bieżącej PV,

- $\check{C}$ jest obserwowaną ceną rynkową,

- $\delta C=\frac{|\Delta C|}{\check{C}}=\frac{\left|\check{C}-C_{0}\right|}{\check{C}}$ jest względnym odchyleniem ceny rynkowej od ceny równowagi,

- $C_{0}$ jest merytorycznie uzasadnioną ceną równowagi.

Ogólnie rzecz biorąc, behawioralna wartość bieżąca BPV jest liczbą rozmytą, która przybliża cenę rynkową $\check{C}$. Może ona zostać opisana jako liczba rozmyta typu LR

$$
B P V=\mathcal{S}\left(V_{\text {min }}, \check{C}, \check{C}, V_{\text {max }}, h, k\right),
$$

która jest określona przez swoją funkcję przynależności $\mu_{B P V}$ zdefiniowaną osobno w przypadku, gdy $\Delta C>0$, oraz w przypadku, gdy $\Delta C \leq 0$. Rysunek 1 pokazuje wykresy funkcji przynależności $\mu_{B P V}(\cdot \mid \Delta C>0)$ oraz $\mu_{B P V}(\cdot \mid \Delta C \leq 0)$ w zależności od znaku odchylenia ceny rynkowej od ceny równowagi.

Jeżeli weźmiemy pod uwagę subiektywne prognozy przyszłych zmian cen, to możemy opisać zorientowaną wartość bieżącą BPV (OBPV) jako skierowaną liczbę rozmytą

gdzie

$$
\overleftrightarrow{B P V}=\overleftrightarrow{\mathcal{S}}\left(V_{s}, \check{C}, \check{C}, V_{e}, L_{B P V}, R_{B P V}\right)
$$

- $\left[V_{s}, V_{e}\right]=\left[V_{\min }, V_{\max }\right] \subset \mathbb{R}^{+}$jest przedziałem wszystkich możliwych wartości BPV,

- $\left(L_{B P V}, R_{B P V}\right)$ jest uporządkowaną parą funkcji początkowej oraz funkcji końcowej.
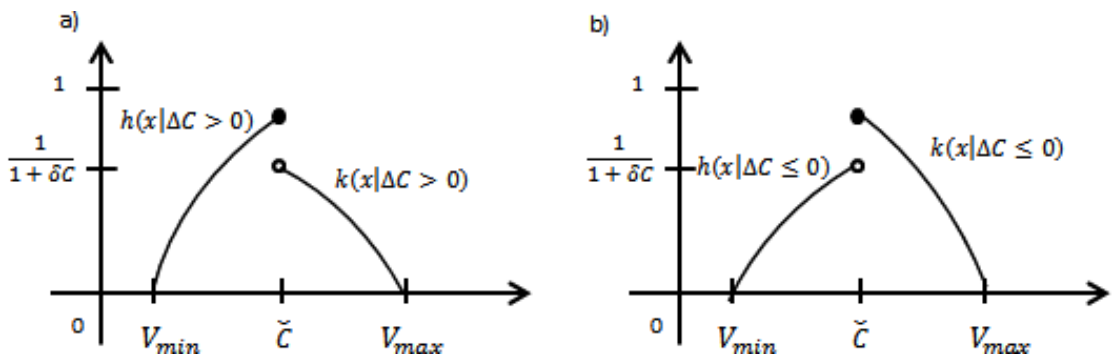

Rys. 1. Wykresy funkcji przynależności behawioralnej wartości bieżącej BPV, gdy a) $\Delta \boldsymbol{C}>\mathbf{0}$, b) $\Delta \boldsymbol{C} \leq \mathbf{0}$

Źródło: opracowanie własne. 
Skierowana behawioralna wartość bieżąca OFBPV $\overleftrightarrow{B P V}$ jest określona przez swoją funkcję przynależności $\mu_{\overparen{B P V}}$ zdefiniowaną za pomocą tożsamości (3) lub (4). Domniemanie wzrostu ceny rynkowej jest określone przez dodatnią orientację skierowanej behawioralnej wartości bieżącej OBPV. Domniemanie spadku ceny rynkowej jest określone przez ujemną orientację OBPV.

Otrzymujemy do rozpatrzenia cztery przypadki skierowanej behawioralnej wartości bieżącej OBPV.

Jeżeli cena rynkowa przewyższa cenę równowagi, czyli $\Delta C>0$, oraz w oparciu o subiektywne przesłanki przewidujemy wzrost ceny rynkowej, to skierowana behawioralna wartość bieżąca OBPV jest opisana za pomocą dodatnio zorientowanej skierowanej liczby rozmytej

$$
\overleftrightarrow{B P V}=\overleftrightarrow{\mathcal{S}}\left(V_{\text {min }}, \check{C}, \check{C}, V_{\text {max }}, h(\cdot \mid \Delta C>0), k(\cdot \mid \Delta C>0)\right)
$$

W tym przypadku wykres funkcji przynależności pokazany jest na rys. 2 .

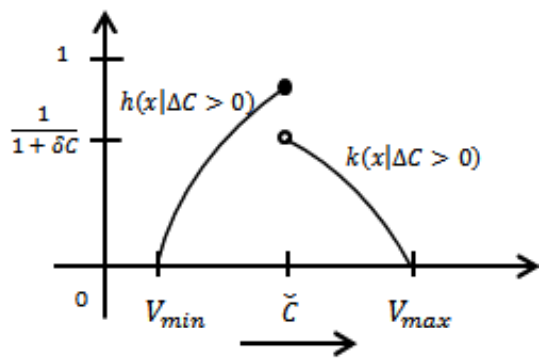

Rys. 2. Wykresy funkcji przynależności dodatnio zorientowanej BPV, gdy $\Delta \boldsymbol{C}>\mathbf{0}$ Źródło: opracowanie własne.

Jeżeli cena rynkowa przewyższa cenę równowagi, czyli $\Delta C>0$, oraz w oparciu o subiektywne przesłanki przewidujemy spadek ceny rynkowej, to skierowana behawioralna wartość bieżąca OBPV jest opisana za pomocą dodatnio zorientowanej skierowanej liczby rozmytej

$$
\overleftrightarrow{B P V}=\overleftrightarrow{\mathcal{S}}\left(V_{\text {max }}, \check{C}, \check{C}, V_{\text {min }}, k(\cdot \mid \Delta C>0), h(\cdot \mid \Delta C>0)\right)
$$

W tym przypadku wykres funkcji przynależności pokazany jest na rys. 3 .

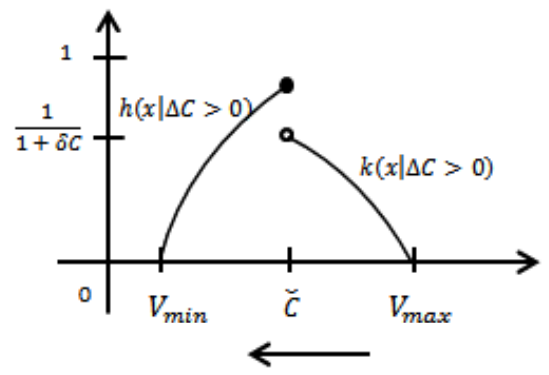

Rys. 3. Wykresy funkcji przynależności ujemnie zorientowanej BPV, gdy $\Delta \boldsymbol{C}>\mathbf{0}$ Źródło: opracowanie własne. 
Jeżeli cena rynkowa nie przewyższa ceny równowagi, czyli $\Delta C \leq 0$, oraz w oparciu o subiektywne przesłanki przewidujemy wzrost ceny rynkowej, to skierowana behawioralna wartość bieżąca OBPV jest opisana za pomocą dodatnio zorientowanej skierowanej liczby rozmytej

$$
\overleftrightarrow{B P V}=\overleftrightarrow{\mathcal{S}}\left(V_{\text {min }}, \check{C}, \check{C}, V_{\text {max }}, h(\cdot \mid \Delta C \leq 0), k(\cdot \mid \Delta C \leq 0)\right)
$$

W tym przypadku wykres funkcji przynależności pokazany jest na rys. 4 .

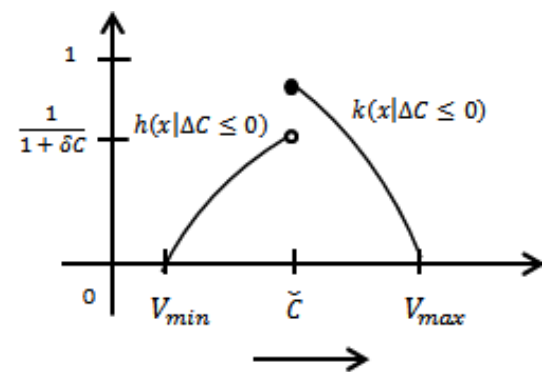

Rys. 4. Wykresy funkcji przynależności dodatnio zorientowanej BPV, gdy $\Delta \boldsymbol{C} \leq \mathbf{0}$

Źródło: opracowanie własne.

Jeżeli cena rynkowa nie przewyższa ceny równowagi, czyli $\Delta C \leq 0$, oraz w oparciu o subiektywne przesłanki przewidujemy spadek ceny rynkowej, to skierowana behawioralna wartość bieżąca OBPV jest opisana za pomocą ujemnie zorientowanej skierowanej liczby rozmytej

$$
\overleftrightarrow{B P V}=\overleftrightarrow{\mathcal{S}}\left(V_{\text {max }}, \check{C}, \check{C}, V_{\text {min }}, k(\cdot \mid \Delta C \leq 0), h(\cdot \mid \Delta C \leq 0)\right)
$$

W tym przypadku wykres funkcji przynależności pokazany jest na rys. 5 .

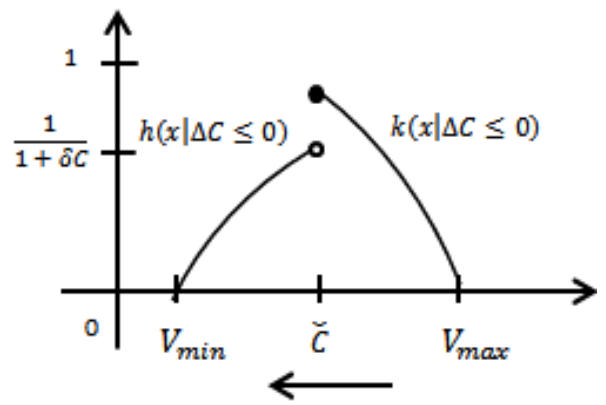

Rys. 5. Wykresy funkcji przynależności ujemnie zorientowanej BPV, gdy $\Delta \boldsymbol{C} \leq \mathbf{0}$ Źródło: opracowanie własne. 
Przykład 1. Dla ustalonego papieru wartościowego wiemy, że obserwowana cena rynkowa $\check{C}=60$. Dodatkowo merytorycznie uzasadniona cena równowagi $C_{0}=40$. Maksymalne dolne i minimalne górne oszacowanie wartości bieżącej PV są odpowiednio równe $V_{\min }=30 \mathrm{oraz} V_{\max }=80$. Na tej podstawie mamy

$$
\begin{gathered}
\Delta C=\check{C}-C_{0}=60-40=20>0, \\
\delta C=\frac{|\Delta C|}{\check{C}}=\frac{20}{60}=\frac{1}{3} .
\end{gathered}
$$

Dodatkowo przewidujemy spadek ceny rynkowej. Wobec tego skierowana behawioralna wartość bieżąca OBPV jest opisana jako ujemnie zorientowana

$$
\overleftrightarrow{B P V}=\mathcal{S}(80 ; 60 ; 60 ; 30 ; k(\cdot \mid 20) ; h(\cdot \mid 20)),
$$

gdzie

$$
\begin{gathered}
h(x)=h(x \mid 20)=\frac{4 x-120}{x+60} \quad \text { dla } x \in[60 ; 30], \\
k(x)=k(x \mid 20)=\left\{\begin{array}{cc}
\frac{3 x-240}{x-140} & \text { dla } x \in[80 ; 60], \\
1 & \text { dla } x=60 .
\end{array}\right.
\end{gathered}
$$

Oznacza to, że rozpatrywana skierowana behawioralna wartość bieżąca jest jednoznacznie określona przez swoją funkcję przynależności

$$
\mu_{B P V}(x \mid 20)=\left\{\begin{array}{cc}
\frac{3 x-240}{x-140} & \text { dla } x \in[80 ; 60], \\
\frac{4 x-120}{x+60} & \text { dla } x \in[60 ; 30], \\
0 & \text { dla } x \notin[80 ; 30],
\end{array}\right.
$$

\section{Skierowany rozmyty czynnik dyskontujący}

Załóżmy, że horyzont czasowy $t>0$ instrumentu finansowego jest ustalony. Wtedy rozpatrywany tutaj papier wartościowy jest określony przez dwie wartości: przewidywaną wartość przyszłą $\mathrm{FV}$ równą $V_{t}$ oraz oszacowaną wartość bieżącą $\mathrm{PV}$ równą $V_{0}$. Podstawową charakterystyką informującą o korzyściach płynących z posiadania danego papieru wartościowego jest prosta stopa zwrotu zdefiniowana jako

$$
r_{t}=\frac{V_{t}-V_{0}}{V_{0}}=\frac{V_{t}}{V_{0}}-1
$$

W praktyce analizy rynków finansowych ryzyko niepewności jest zwykle opisywane jako rozkład prawdopodobieństwa stopy zwrotu obliczonej dla $V_{0}=\breve{C}$. Za Markowitzem [Markowitz 1952] zakładamy, że prosta stopa zwrotu ma rozkład normalny $N(\bar{r}, \sigma)$. Wtedy oczekiwany czynnik dyskontujący $\bar{v} \in \mathbb{R}$ jest określony wzorem

$$
\bar{v}=\frac{1}{1+\bar{r}} \text {. }
$$


W pracy [Łyczkowska-Hanćkowiak, Piasecki 2018b] oczekiwany czynnik dyskontujący $\overleftrightarrow{\mathcal{V}} \in \mathbb{K}$ był rozpatrywany w przypadku, gdy $V_{0}=\overleftrightarrow{P V}$, gdzie wartość bieżąca PV jest określona za pomocą wzoru (2). Wyniki tam otrzymane pozwalają stwierdzić, że jeżeli mamy

$$
V_{0}=\overleftrightarrow{B P V}=\overleftrightarrow{\mathcal{S}}\left(V_{s}, \check{C}, \check{C}, V_{e}, L_{B P V}, R_{B P V}\right),
$$

to oczekiwany czynnik dyskontujący $\overleftrightarrow{\mathcal{V}} \in \mathbb{K}$ może zostać opisany jako skierowana liczba rozmyta

$$
\overleftrightarrow{\mathcal{V}}=\overleftrightarrow{\mathcal{S}}\left(\frac{V_{S} \cdot \bar{v}}{\check{C}}, \bar{v}, \bar{v}, \frac{V_{e} \cdot \bar{v}}{\check{C}}, L_{V}, R_{V}\right)
$$

gdzie

$$
\begin{aligned}
& L_{V}(x)=L_{B P V}\left(\frac{x \cdot \breve{C}}{\bar{v}}\right), \\
& R_{V}(x)=R_{B P V}\left(\frac{x \cdot \breve{C}}{\bar{v}}\right) .
\end{aligned}
$$

Przyjmijmy teraz

$$
\begin{aligned}
& \eta(x)=h\left(\frac{x \cdot \check{C}}{\bar{v}}\right), \\
& \kappa(x)=k\left(\frac{x \cdot \check{C}}{\bar{v}}\right) .
\end{aligned}
$$

Korzystając z (14) otrzymujemy następujące wnioski:

jeżeli $\overleftrightarrow{B P V}$ określona jest wzorem (7), to oczekiwany czynnik dyskontujący $\overleftrightarrow{\mathcal{V}} \in \mathbb{K}$ opisany jest jako skierowana liczba rozmyta postaci

$$
\overleftrightarrow{\mathcal{V}}=\overleftrightarrow{\mathcal{S}}\left(\frac{V_{\min } \cdot \bar{v}}{\check{C}}, \bar{v}, \bar{v}, \frac{V_{\max } \cdot \bar{v}}{\check{C}}, \eta(\cdot \mid \Delta C>0), \kappa(\cdot \mid \Delta C>0)\right)
$$

jeżeli $\overleftrightarrow{B P V}$ określona jest wzorem (8), to oczekiwany czynnik dyskontujący $\overleftrightarrow{\mathcal{V}} \in \mathbb{K}$ opisany jest jako skierowana liczba rozmyta postaci

$$
\overleftrightarrow{\mathcal{v}}=\overleftrightarrow{\mathcal{S}}\left(\frac{V_{\max } \cdot \bar{v}}{\check{c}}, \bar{v}, \bar{v}, \frac{V_{\min } \cdot \bar{v}}{\check{C}}, \kappa(\cdot \mid \Delta C>0), \eta(\cdot \mid \Delta C>0)\right)
$$

jeżeli $\overleftrightarrow{B P V}$ określona jest wzorem (9), to oczekiwany czynnik dyskontujący $\overleftrightarrow{\mathcal{V}} \in \mathbb{K}$ opisany jest jako skierowana liczba rozmyta postaci

$$
\overleftrightarrow{\mathcal{v}}=\overleftrightarrow{\mathcal{S}}\left(\frac{V_{\min } \cdot \bar{v}}{\check{C}}, \bar{v}, \bar{v}, \frac{V_{\max } \cdot \bar{v}}{\check{C}}, \eta(\cdot \mid \Delta C \leq 0), \kappa(\cdot \mid \Delta C \leq 0)\right)
$$

jeżeli $\overleftrightarrow{B P V}$ określona jest wzorem (10), to oczekiwany czynnik dyskontujący $\overleftrightarrow{V} \in \mathbb{K}$ opisany jest jako skierowana liczba rozmyta postaci

$$
\overleftrightarrow{\mathcal{v}}=\overleftrightarrow{\mathcal{S}}\left(\frac{V_{\max } \cdot \bar{v}}{\check{C}}, \bar{v}, \bar{v}, \frac{V_{\min } \cdot \bar{v}}{\check{C}}, \kappa(x \cdot \mid \Delta C \leq 0), \eta(\cdot \mid \Delta C \leq 0)\right)
$$


Zauważmy, że orientacja oczekiwanego czynnika dyskontującego jest zawsze taka sama jak orientacja behawioralnej wartości bieżącej BPV, która go definiuje.

Przykład 2. Dla papieru wartościowego opisanego w przykładzie 1 zakładamy, że jego prosta stopa zwrotu ma rozkład normalny $N(0,25,0,1)$. Wtedy oczekiwany czynnik dyskontujący $\overleftrightarrow{\mathcal{V}} \in \mathbb{K}$ jest opisany jako ujemnie zorientowana liczba rozmyta postaci

$$
\overleftrightarrow{\mathcal{V}}=\overleftrightarrow{\mathcal{S}}(1,0667 ; 0,8 ; 0,8 ; 0,4 ; \kappa(\cdot \mid 20) ; \eta(\cdot \mid 20))
$$

gdzie

$$
\begin{aligned}
& \eta(x)=\eta(x \mid 20)=\frac{300 \cdot x-120}{75 \cdot x+60} \text { dla } x \in[0,8 ; 0,4], \\
& \kappa(x)=\kappa(x \mid 20)=\left\{\begin{array}{c}
\frac{225 \cdot x-240}{75 \cdot x-140} \text { dla } x \in[1,0667 ; 0,8[ \\
1 \text { dla } x=0,8 .
\end{array}\right.
\end{aligned}
$$

Oznacza to, że rozpatrywana skierowana behawioralna wartość bieżąca OBPV jest jednoznacznie określona przez swoją funkcję przynależności określoną wzorem

$$
\mu_{B P V}(x \mid 20)=\left\{\begin{aligned}
& \frac{225 \cdot x-240}{75 \cdot x-140} \text { dla } x \in[1,0667 ; 0,8] \\
& \frac{300 \cdot x-120}{75 \cdot x+60} \text { dla } x \in[0,8 ; 0,4], \\
& 0 \text { dla } x \notin[1,0667 ; 0,4]
\end{aligned}\right.
$$

\section{Zakończenie}

Podsumowując, należy stwierdzić, że behawioralna wartość bieżąca została opisana jako skierowana liczba rozmyta. Liczba rozmyta, która określa BPV, ma dodatnią orientację, kiedy oczekujemy (na podstawie subiektywnych przesłanek), że cena rynkowa wzrośnie. W przeciwnym przypadku ma ona ujemną orientację. Model behawioralnej wartości bieżącej może być dobrym narzędziem do analizy ekonomicznej oraz modelowania ekonomicznego. Pozwala to na przypuszczenie, że otrzymane wnioski zostaną wykorzystane do analizy portfela. Wyniki pracy w pełni przekonują, że wykorzystanie skierowanych liczb rozmytych ułatwi analizę instrumentów finansowych o nieprecyzyjnie oszacowanych wartościach. Otrzymane wyniki mogą być stosowane na przykład w modelach decyzyjnych opisanych w pracy [Piasecki 2014]. Pozwala to na stwierdzenie, że wskazany jest dalszy rozwój teorii finansów rozmytych w oparciu o skierowane liczby rozmyte. 


\section{Literatura}

Dubois D., Prade H., 1978, Operations on fuzzy numbers, International Journal of System Science, vol. 9, s. 613-629, https://doi.org/10.1080/00207727808941724.

Dubois D., Prade H., 1980, Fuzzy Sets and systems: Theory and Applications, Academic Press, New York.

https://doi.org/10.1111/j.1540-6261.1952.tb01525.x.

Kosiński W., 2006, On fuzzy number calculus, Int. J. Appl. Math. Comput. Sci., 16(1), s. 51-57.

Kosiński W., Prokopowicz P., Ślęzak D., 2002, Fuzzy Reals with Algebraic Operations: Algorithmic approach, [w:] Kłopotek M.A., Wierzchoń S.T., Michalewicz M. (red.), Intelligent Information Systems 2002, Advances in Soft Computing, vol 17, Physica, s. 311-320, https://doi.org/ 10.1007/978-3-7908-1777-5 33.

Kosiński W., Prokopowicz P., Ślęzak D, 2003, Ordered fuzzy numbers, Bulletin of the Polish Academy of Sciences, Sér. Sci. Math., 51 (3), s. 327-338.

Łyczkowska-Hanćkowiak A., 2017a, Behavioural present value determined by ordered fuzzy number, SSRN Electronic Journal, https://doi.org/10.2139/ssrn.2988243.

Łyczkowska-Hanćkowiak A., 2017b, Behawioralna wartość bieżaca w postaci skierowanych liczb rozmytych, Optimum. Studia Ekonomiczne, nr 3 (87), s. 122-137, DOI10.15290/ose. 2017. 03.87.09.

Łyczkowska-Hanćkowiak A., Piasecki K., 2018a, On representation of Japanese candlesticks by ordered fuzzy numbers, [w:] W. Szkutnik i in. (red.), $9^{\text {th }}$ International Scientific Conference "Analysis of International Relations 2018, Methods and Models of Regional Development, Winter Edition", conference proceedings, UE, Katowice.

Łyczkowska-Hanćkowiak A., Piasecki K., 2018b, The expected discount factor determined for present value given as ordered fuzzy number, [w:] W. Szkutnik i in. (red.), $9^{\text {th }}$ International Scientific Conference "Analysis of International Relations 2018. Methods and Models of Regional Development. Winter Edition", conference proceedings, UE, Katowice.

Markowitz H.S.M., 1952, Portfolio Selection, Journal of Finance, vol. 7 (1), s. 77-91.

Piasecki K., 2011, Behavioural present value, SSRN Electronic Journal, https:/dx.doi. org/10.2139/ssrn.1729351.

Piasecki K., 2014, On imprecise investment recommendations, Studies in Logic, Rhetoric and Grammar. vol. 37, s. 179-194, https://doi.org/10.2478/slrg-2014-0024.

Piasecki K., 2018, Revision of the Kosinski's theory of ordered fuzzy numbers, Axioms, vol. 7 (1), https://doi.org/10.3390/axioms7010016.

Piasecki K., Siwek J., 2015, Behavioural present value defined as fuzzy number a new approach, Folia Oeconomica Stetinensia, vol. 15(2), s. 27-41, https://doi.org/10.1515/foli-2015-0033.

Piasecki K., Siwek J., 2018, Two-asset portfolio with triangular fuzzy present values - an alternative approach, [w:] T. Choudhry, J. Mizerka (red.), Contemporary Trends in Accounting, Finance and Financial Institutions (ICAFFI), Poznan 2016, Springer Proceedings in Business and Economics, Berlin, Springer Verlag, https://doi.org/ 10.1007/978-3-319-72862-9_2. 